\title{
Flexural Reinforced Concrete Elements Residual Stresses of Fibres with Limited Reinforcement Bond
}

\author{
Goaras Andriušis ${ }^{1}$, Algirdas Augonis ${ }^{1}$, Mindaugas Augonis ${ }^{*}$, Šarūnas Kelpša ${ }^{1}$, Tadas Zingaila² \\ ${ }^{1}$ Kaunas University of Technology, Faculty of Civil Engineering and Architecture, Studentu st. 48, LT-51367 Kaunas, Lithuania \\ ${ }^{2} U A B$ “Evikta”, Statybininku st. 12, LT-50127 Kaunas, Lithuania
}

*Corresponding author: mindaugas.augonis@ktu.lt

cross'ref http://dx.doi.org/10.5755/j01.sace.2.3.4285

This article presents calculation of residual stresses of steel fibre and ordinary reinforcement reinforced concrete elements, with limited bond between reinforcement and concrete. This calculation is based on the relationship of cracked middle section crack width and curvature. This relationship is obtained from experimental results, by testing reinforced concrete elements, without steel fibre. The aim of investigation is to find out the force in ordinary reinforcement as the main member evaluated residual stress in fibre. These calculations there were supported on several assumptions that not significantly evaluated the results. In article are described test methods and materials, given schemes of tests and calculations.

Keywords: steel fibre, residual stress, bond of reinforcement, cracking, deflection.

\section{Introduction}

Currently fibres are applied more often not only for concrete, but also for reinforced concrete bending elements, in order to increase the stiffness and cracking resistance of elements. There are various types of fibres, however bending elements are more effective when steel fibre is being used. Small amount of steel fibres will not have essential influence on bending element behaviour, however sufficient amount can significantly to reduce the normal crack width and deflection (Vandewale L. 2000, Kaklauskas G. 2011, Grimaldi A. et al. 2004). Steel fibre, as well as reinforcement, does not have significant effect until the moment of crack opening. However, after this moment it can influence tension zone behaviour, even so increasing load bearing capacity (Jones P. A et al. 2008). It should be mentioned that the behaviour of steel fibre and ordinary reinforcement reinforced concrete elements is not sufficiently analysed until now, especially with limited bond between reinforcement and concrete. The influence of technological factors, which can significantly adjust the experimental results, also complicates such studies. So, a slight adjustment of specimen making technology can give perceptible deviation of results. Taking into account that element always starts fracturing in the weakest section, it is difficult to simulate it by natural experiment. Due to these and other reasons the scatter of results of steel fibre reinforced concrete specimens is relatively large and it is not easy to predict it sufficiently accurately. It is worth to mention that the scatter of results of steel fibre and ordinary reinforcement reinforced concrete elements is smaller than steel fibre reinforced concrete elements, because in this case the behaviour of tension zone is determined not only by amount and orientation of fibres in section, but also by longitudinal reinforcement which always is in the design position, and its behaviour can be sufficiently accurately predicted.

Currently fibre reinforced concrete is usually tested according to LST EN 14651 or DIN 1048 requirements. According to LST EN 14651 element is tested when one concentrated force is acting in the middle section, and specimen has pre-made notch in bottom. This notch is intended to control opening normal section, because in order to determine the fracture energy the relationship curve of crack width and force is required. Taking into account that based on experimental results crack width sufficiently well correlates with element deflection (Barr B. I. G. et al. 2003), the appropriate crack width can be calculated from determined deflection. Therefore, in this case, weakened section cracking describes element deflection, i.e. this section curvature. If tests would be performed with steel fibre and ordinary reinforcement reinforced concrete element, there would not be such correlation between deflection and crack width, because the crack in weakened section would have developed significantly slower than in steel fibre reinforced concrete element. In this case, in order to get correlation between deflection and crack width both - tension concrete 
near the crack and tension reinforcement stresses should be evaluated. According to DIN 1048 the influence on steel fibre is evaluated slightly different. The cross-section is not weakened by a notch, but changed loading scheme only. In the middle zone two concentrated loads are added, to get pure bending zone where in its weakest section the normal crack will open. In this case behaviour of fibre is more accurately evaluated, taking into account that fibre is randomly distributed. Therefore, normal crack will start to develop in that section (in the pure bending zone), in which the content of steel fibre and its distribution will have a minimal influence on crack behaviour in tension zone. In this regard, DIN standard is more accurate than LST EN. In any case, if steel fibre and ordinary reinforcement reinforced concrete element is analysed, need to know its state of stress, in order to presume relationship between deflection and force. When there is sufficient bond between reinforcement and concrete, relationship of deformations is linear, however if the bond is not sufficient, according to this relationship we will not determine the force value in reinforcement. This value can be determined according to experimental results, which are given in Section 3.

\section{Test Methods and Materials}

Concrete specimens were prepared from average strength concrete class $\mathrm{C} 30 / 37$. According to selected concrete class, concrete mix was designed with $\mathrm{W} / \mathrm{C}$ ratio 0.48 .

According to this concrete mix composition, steel fibre reinforced concrete and steel fibre and ordinary reinforcement reinforced concrete elements were made, using steel fibre packets with hooked ends. Fibres are not high class because fibre length is $55 \mathrm{~mm}$. Length and diameter ratio does not exceed 60, and anchorage parts do not make sufficient bond with concrete. During experiment content of fibres was changed only, when components of concrete mix were constant.

To determine concrete strength of made specimens, $70 \times 70 \times 70 \mathrm{~mm}$ concrete cubes were formed. Specimens were hardened in $\sim 20^{\circ} \mathrm{C}$ temperature water for 28 days. In parallel, during making of each beam, 3 cubes were made to determine concrete compressive strength.

For bending tests 3 beams from each series were made. In first stage, 3 reinforced concrete beams without fibres were made, which were reinforced with S 400 class, $6 \mathrm{~mm}$ diameter plain reinforcement. In second stage analogical beams were made (3 units of each), which were reinforced with S 400 class, $6 \mathrm{~mm}$ diameter plain reinforcement, by adding to beams respectively $20 \mathrm{~kg} / \mathrm{m}^{3}, 35 \mathrm{~kg} / \mathrm{m}^{3}$ and $50 \mathrm{~kg} / \mathrm{m}^{3}$ steel fibre. Total, 12 beams were made $100 \times 100 \times 400 \mathrm{~mm}$. As well as cubes, beams were hardened for 28 days, and kept in $+18-+20^{\circ} \mathrm{C}$ temperature water. After 28 days, beams were taken from water, dried and tested according to Germany standardized testing method DIN 1045-1.

Beams were loaded with two concentrated forces, one-third of the span length from the supports (according to scheme given in Fig. 1 and 2). Loading was performed according to deformations, i.e. the force was added so that the velocity of press cylinder would be $0.2 \mathrm{~mm} / \mathrm{min}$ (DIN 1045-1). Thus, during the test, two gauges were used, which precision was $0.001 \mathrm{~mm}$. First - was used to control the velocity of press cylinder (number 1 in Fig. 2), second - to determine the element deflection (number 2 in Fig. 2). In order to determine deflection in the middle of the element, holder was fixed in the supporting sections, which does not deform in the middle of the element with respect to the supports. Other holder of deformations gauges was fixed in the middle of the element. When the beam starts to bend, second holder moves down together with beam, recording the size of deflection with respect to the first holder.

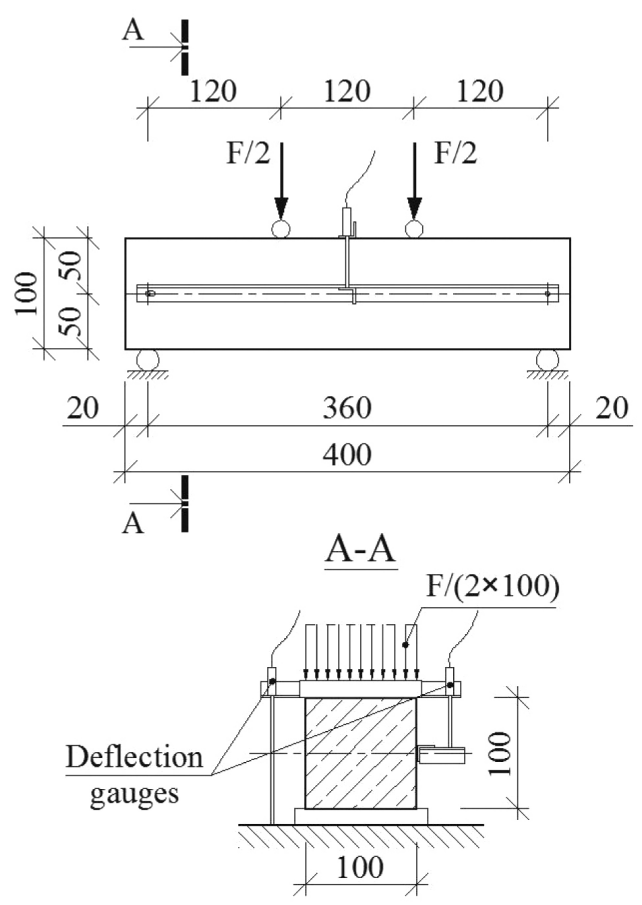

Fig. 1. The scheme of test

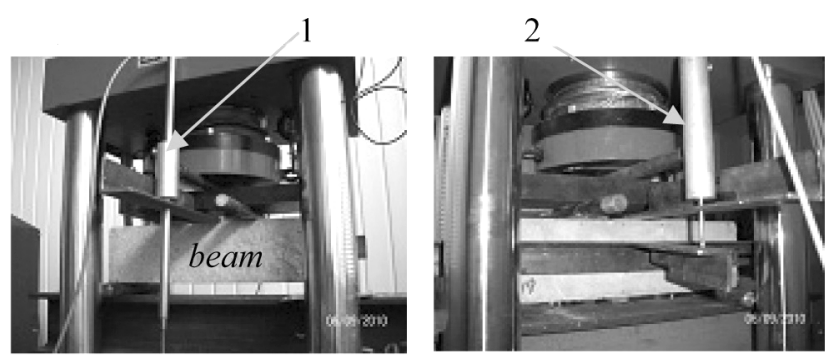

Fig. 2. The specimen prepared to test. View from both sides. (1 - gauge to control load velocity, 2 - gauge for deflection measurement)

\section{Test Results}

First of all, compression strength of concrete was determined. As mentioned in introduction, $70 \times 70 \times 70 \mathrm{~mm}$ cubes were tested, and obtained strengths were recalculated according to the strengths of standard cubes $150 \times 150 \times 150 \mathrm{~mm}$. Total, 3 specimens were made from each composition of concrete. Obtained values are given in table 1 . 
Table 1. Concrete strengths

\begin{tabular}{|c|c|c|c|c|c|}
\hline \multirow{2}{*}{ No. } & \multirow{2}{*}{$\begin{array}{l}\text { Content of } \\
\text { fibre }\end{array}$} & \multicolumn{3}{|c|}{ Concrete strengths, MPa } & \multirow{2}{*}{$\begin{array}{c}\text { Average } \\
\text { strength, } \\
\mathrm{MPa}\end{array}$} \\
\hline & & $\mathbf{I}$ & II & III & \\
\hline 1 & - & 37,25 & 36,76 & 34,58 & 36,20 \\
\hline 2 & $20 \mathrm{~kg} / \mathrm{m}^{3}$ & 33,8 & 32,67 & 31,61 & 32,69 \\
\hline 3 & $35 \mathrm{~kg} / \mathrm{m}^{3}$ & 35,13 & 33,84 & 36,33 & 35,10 \\
\hline 4 & $50 \mathrm{~kg} / \mathrm{m}^{3}$ & 36,98 & 37,33 & 38,58 & 37,63 \\
\hline
\end{tabular}

As shown in Fig. 3, amount of fibre slightly reduced compression strength of concrete, and only sufficiently large fibre amount $\left(50 \mathrm{~kg} / \mathrm{m}^{3}\right)$, positively influenced compression strength.

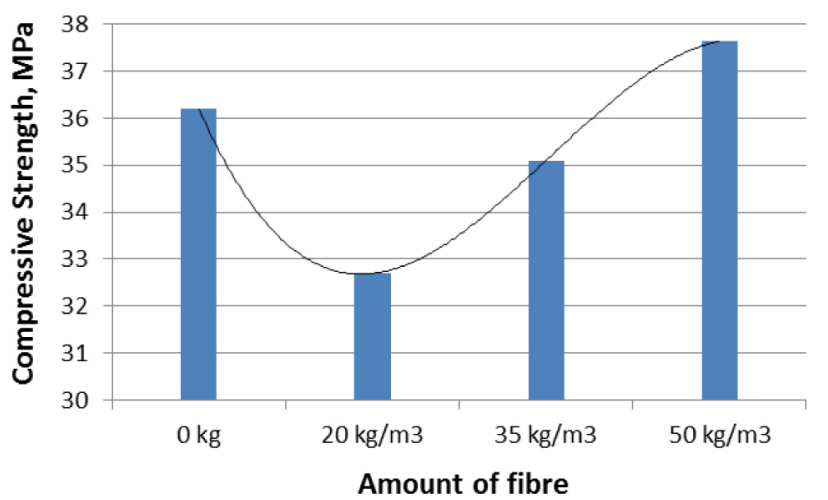

Fig 3. The relationship between amount of fibres and compression strength of concrete

As mentioned above, testing efficiency of steel fibre in reinforced concrete element, 4 series with 3 specimens were tested, when amount of steel fibre was changed. Test results are given in Fig. 4 and Fig. 5.

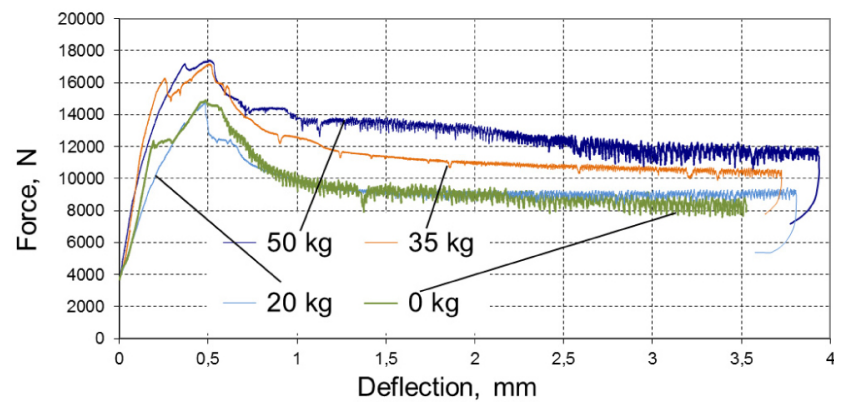

Fig 4. The relationship of load and press cylinder displacement

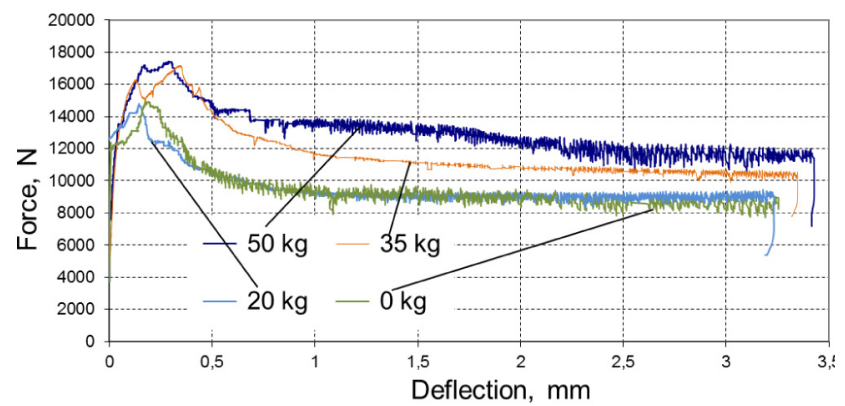

Fig 5. The relationship of load and specimen deflection

\section{Calculation of Fibre Residual Stress}

Assuming that anchorage length of reinforcement is same in concrete and in steel fibre reinforced concrete we can accept that when identical crack widths exist, stresses in reinforcement are the same in reinforced concrete and in steel fibre and ordinary reinforcement reinforced concrete elements.

Certainly, in this case, identical crack width will be achieved with different bending moments (in element with steel fibre, it will be achieved at larger bending moment). Thus, it can be stated that, at the identical crack widths, stresses in reinforcement will be the same, as well as the same force in reinforcement $F_{s, b o n d}$.

When there is sufficient bond between reinforcement and concrete, above mentioned value can be calculated according to scheme, given in Fig. 6:

$$
F_{c}=F_{s, \text { bond }}, F_{c}=\frac{1}{2} \varepsilon_{c} E_{c} b x, F_{s, \text { bond }}=\varepsilon_{s} E_{s} A_{s},
$$

where $b$-width of section, $\varepsilon_{c}$ and $\varepsilon_{s}-$ strain of concrete and reinforcement, $E_{c}$ and $E_{s}$ - elastic modulus of concrete and reinforcement, $x$ - height of compression zone.

Then equilibrium equations will be:

$$
\left\{\begin{array}{l}
\frac{1}{2} \varepsilon_{c} E_{c} b x=\varepsilon_{s} E_{s} A_{s} \\
\sigma_{s} A_{s}(d-x / 3)=M
\end{array} .\right.
$$

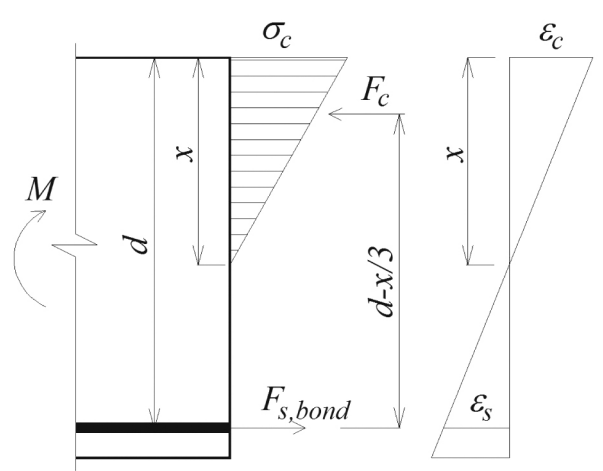

Fig 6. The scheme for calculation of reinforcement force

From strain curve expressed $\varepsilon_{s}=\frac{\varepsilon_{c}(d-x)}{x}$, we get

$\frac{1}{2} E_{c} b x^{2}+E_{s} A_{s} x-E_{s} A_{s} d=0$.

The real solution of this equation

$$
x=\frac{\alpha_{s} A_{s} \sqrt{4+8 b d / \alpha_{s} A_{s}}-2 \alpha_{s} A_{s}}{2 b},
$$

where $\alpha_{s}=E_{s} / E_{c}, A_{s}-$ area of reinforcement, $b$ - width of element.

Then stresses in reinforcement

$\sigma_{s}=\frac{M}{A_{s}(d-x / 3)}$. 
However, when there is a limited bond between reinforcement and concrete, relationship between reinforcement and concrete strains can be different, depending on the size of stresses.

Taking into account that crack width has linear correlation with deflection, then force, determined by testing reinforced concrete element at the deflection increment $\Delta f_{\text {crc }}$ (Fig. 7), would be the same as in steel fibre and ordinary reinforcement reinforced concrete element, i.e. $F_{s, \text { bond } 1}=F_{s, \text { bond } 2}=F_{s, \text { bond }}$.

The member $\Delta f_{c r c}=f-f_{e l}$, where $\Delta f_{c r c}$-deflection increment when crack is appeared, $f_{e l}$-deflection from elastic strain. The deflection from elastic strain evaluated because the mentioned deflection increment in both elements (with fibre ,2" and without it „,") will be reach at the different bending moments values $M_{2}>M_{1}$. It is mean that deflection from elastic strain will be differ also, i.e.

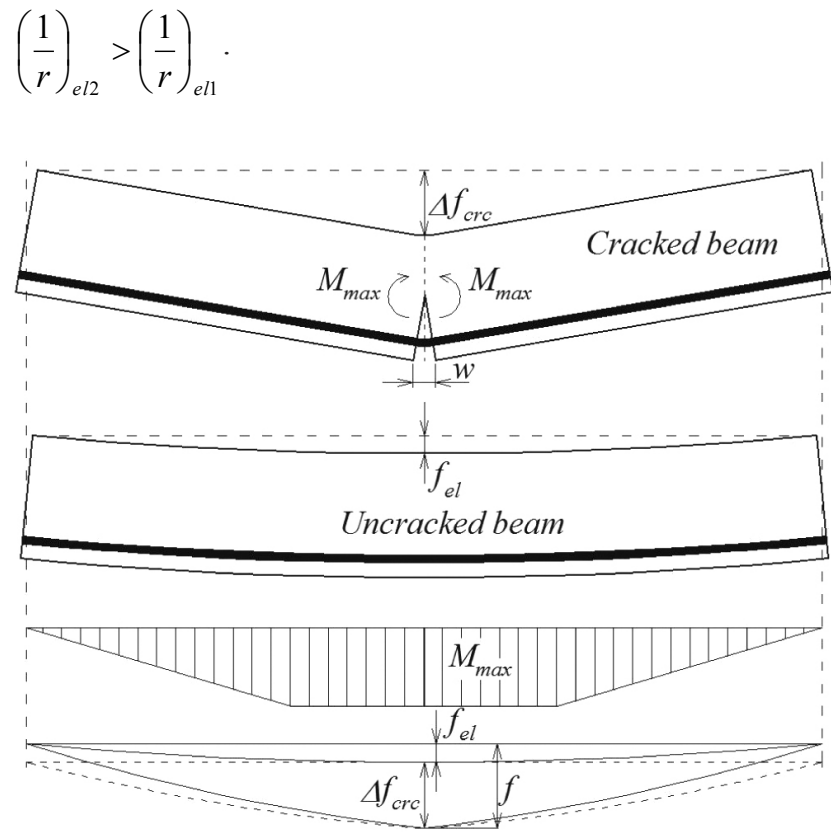

Fig. 7. The calculation scheme of $\Delta f_{c r c}$ and $f_{e l}$

In this case there the elastic modulus of concrete and fibre reinforced concrete assumed as equal to $E_{c}$. After reviewing such assumptions and calculation principles the force $F_{s, b o n d}$ could be find out according to relationship of deflection and force $F$ of element with ordinary reinforcement only (Fig. 8).

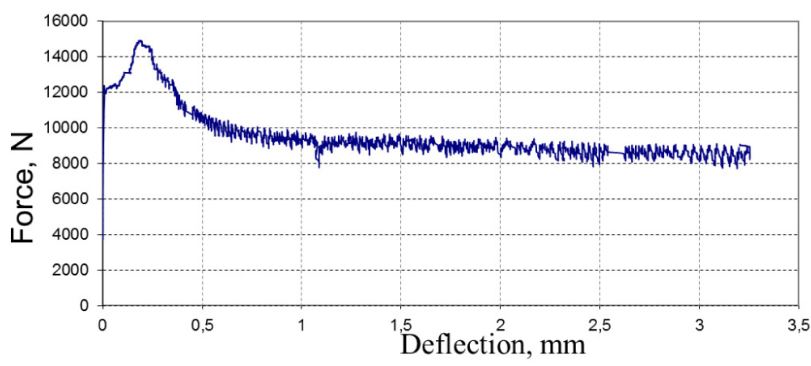

Fig. 8. The relationship of force and deflection of element with ordinary reinforcement only
When the crack opens in element with ordinary reinforcement only the relationship of deflection and crack width could express

$$
\frac{\Delta f_{c r c}}{0.5 l} \approx \frac{0.5 w}{h_{c r c}}
$$

where $l$-span length, $w$ - crack width, $h_{c r c}-$ crack height.

Then the curvature in middle cracked section can be calculated as (Fig. 6)

$$
\left(\frac{1}{r}\right)_{c r c}=\frac{\varepsilon_{c}}{x} \approx \frac{\Delta f_{c r c}}{0.5 l}
$$

According to equations system (1) the expression could be rewritten

$$
\frac{M}{d-x / 3}=\frac{1}{2} \varepsilon_{c} E_{c} b x=\frac{1}{2}\left(\frac{1}{r}\right)_{c r c} E_{c} b x^{2} .
$$

So, the compression height will be obtain from cube equation

$$
x^{3}-3 d x^{2}+\frac{6 M}{b E_{c}\left(\frac{1}{r}\right)_{c r c}}=0 .
$$

After solution of cube equation we obtain the height of compression zone and the bond force in ordinary reinforcement also

$$
F_{s, b o n d}=\frac{1}{2} \varepsilon_{c} E_{c} b x=\frac{M}{d-x / 3} .
$$

When the steel fibre reinforced concrete is analysing the reinforcement bond force could be expressed as function of variables $\left(\frac{1}{r}\right)_{c r c}$ or $\Delta f_{c r c}$, i. e. $F_{s, b o n d}=z\left(\left(\frac{1}{r}\right)_{c r c}\right)$ or $F_{s, b o n d}=g\left(\Delta f_{c r c}\right)$ (Fig. 9). Such functions could express according to results of test of element with ordinary reinforcement only.

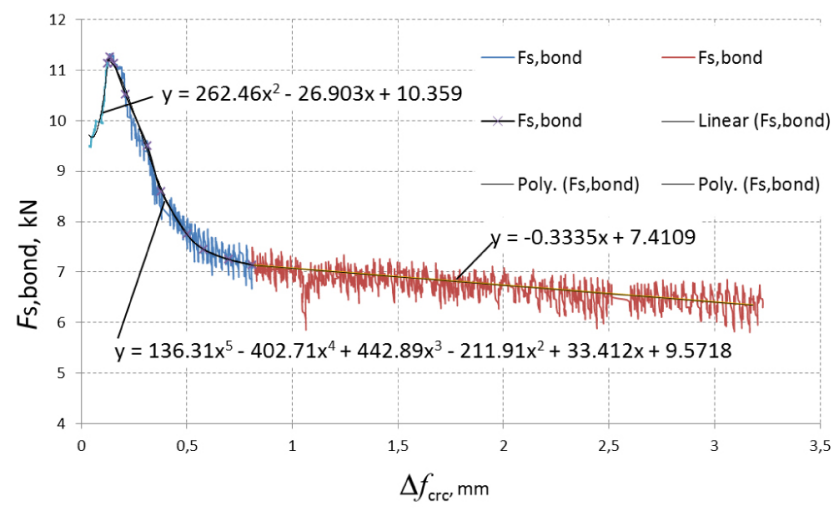

Fig. 9. The expression of relationship of bond force $F_{s, b o n d}$ and deflection increment $\Delta f_{\text {crc }}$ by polynomial functions

So, if we let to assume that at the same curvature of middle section of cracked element (with any amount of fibre) the bond force of ordinary reinforcement remains the same, independently on amount of fibres, the residual stress of fibre could be expressed at any value of curvature $\left(\frac{1}{r}\right)_{c r c}$ 
or deflection increment $\Delta f_{c r c}$. Of course, for it calculation more practically to use the relationship $F_{s, \text { bond }}-f$, than $F_{s, \text { bond }}-\Delta f_{c r c}$, because in such way we would escape the additional calculation of $\Delta f_{c r c}$. On analysis of these two relationships we can see that $F_{s, b o n d}$ depends on $\Delta f_{c r c}$ and $f$ (when crack is appeared) very similar (Fig. 10). So, in this way we could take into account the relationship $F_{s, b o n d}-f$ without significant calculation error.

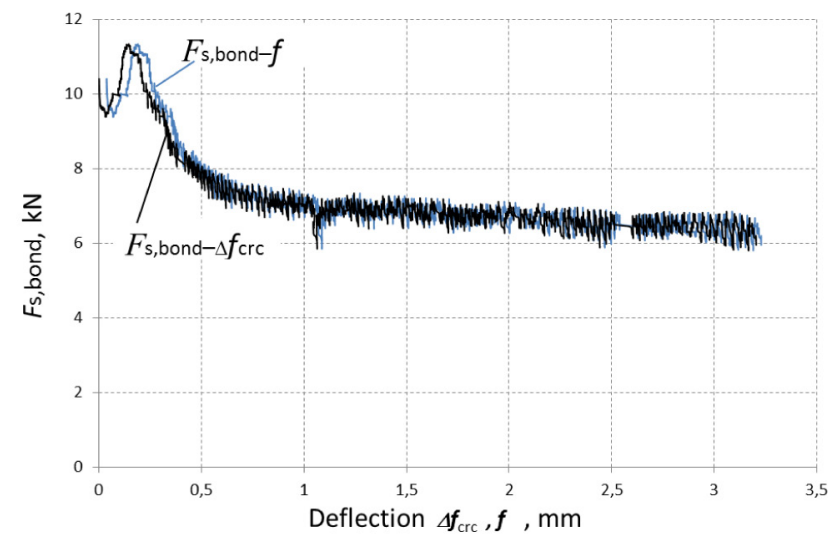

Fig. 10. The relationship of element ordinary reinforcement bond force $F_{s, \text { bond }}$ and deflection $f$ and deflection increment $\Delta f_{\text {crc }}$

Practically, the relationship $F_{s, \text { bond }}-f$ could be expressed as polynomial function (Fig. 11). For more accuracy there were expressed two functions:

$$
\begin{aligned}
& F_{s, \text { bond }}=-20989.28 f^{4}+9108.41 f^{3}- \\
& -1247.37 f^{2}+67.96 f+8.32 \\
& F_{s, \text { bond }}=-0.621 f^{5}+5.83 f^{4}-20.79 f^{3}+ \\
& +35.06 f^{2}-28.24 f+15.63
\end{aligned}
$$

The first function has range from crack point to maximum force $F_{\max }$ and another one from $F_{\max }$ to maximum deflection value.

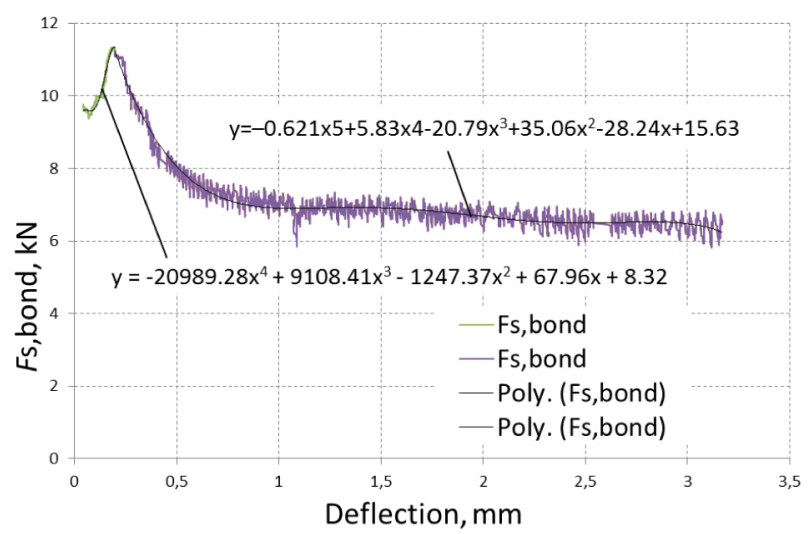

Fig. 11. The expression of $F_{s, b o n d}-f$ relationship by polynomial functions

According to these functions we can calculate the residual stress (according to scheme in Fig.12) in fibre at any deflection value after the crack is appeared.
In such case the average residual stress could be obtained from equations systems:

$$
\left\{\begin{array}{c}
\frac{1}{2} \sigma_{c} b x \approx \sigma_{f} b(h-x)+F_{s, b o n d} \\
F_{s, b o n d}(d-x / 3)+\sigma_{f} b(h-x)(2 x / 3+h / 2-x / 2)=M
\end{array}\right.
$$

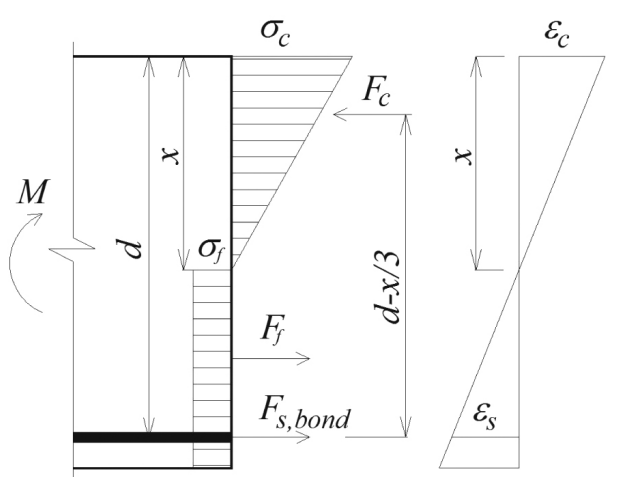

Fig. 12. The scheme for calculation of average residual stress

From the second equations of equations system expressed the $\sigma_{f}$

$$
\sigma_{f}=\frac{M-f_{s, \text { bond }}(d-x / 3)}{b((h-x)(h / 2+x / 6))}
$$

and in consider to equilibrium equation of horizontal forces we can write

$$
\frac{1}{2} E_{c}\left(\frac{1}{r}\right)_{c r c} b x^{2}=\frac{M-F_{s, b o n d}(d-x / 3)}{h / 2+x / 6}+F_{s, b o n d} .
$$

So, we get another cube equation that could be rewritten as

$$
x^{3}+3 h x^{2}-\frac{6 F_{s, i n k}}{b E_{c}\left(\frac{1}{r}\right)_{c r c}} x+\frac{F_{s, i n k}(d-h / 2)-M}{b E_{c}\left(\frac{1}{r}\right)_{c r c}}=0 .
$$

From equation (15) we can get the height of compression zone and from equation (13) - the average residual stress. After solving such stress for elements with differ amount of fibres the relationships of $\sigma_{f}$ and deflections are presented in Fig. 13.

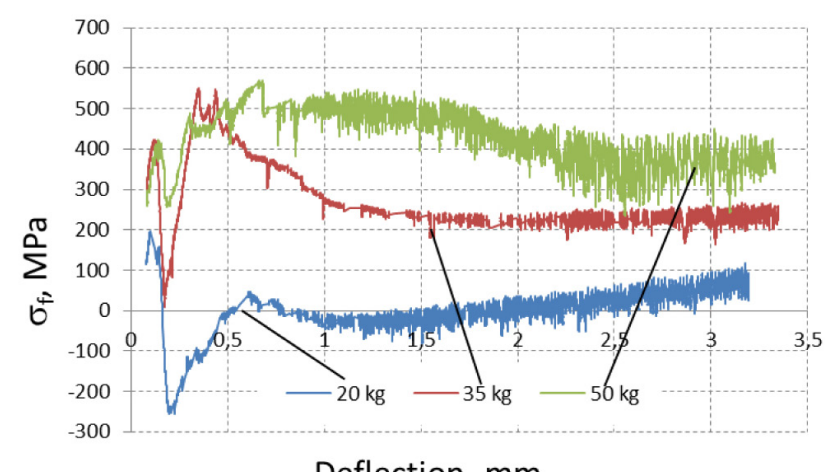

Deflection, $\mathrm{mm}$

Fig. 13. The relationship of average residual stress and deflections of elements with different amount of fibres 
In Fig. 13 we can see that at the range of deflection from 0.18 to 0.52 and from 0.73 to 2.0 the average residual stress of element with $20 \mathrm{~kg}$ fibres is obtained as negative. This is because of reason that at these ranges for element with $20 \mathrm{~kg}$ fibres the force that correspond the displacement velocity of press cylinder was less than the same force for element without any fibres. In this case we can to describe that quite small amount of fibres could decrease the strength properties of element.

The relationship of $\sigma_{f}$ and $f$ expressed as polynomial function is presented in Fig. 14.

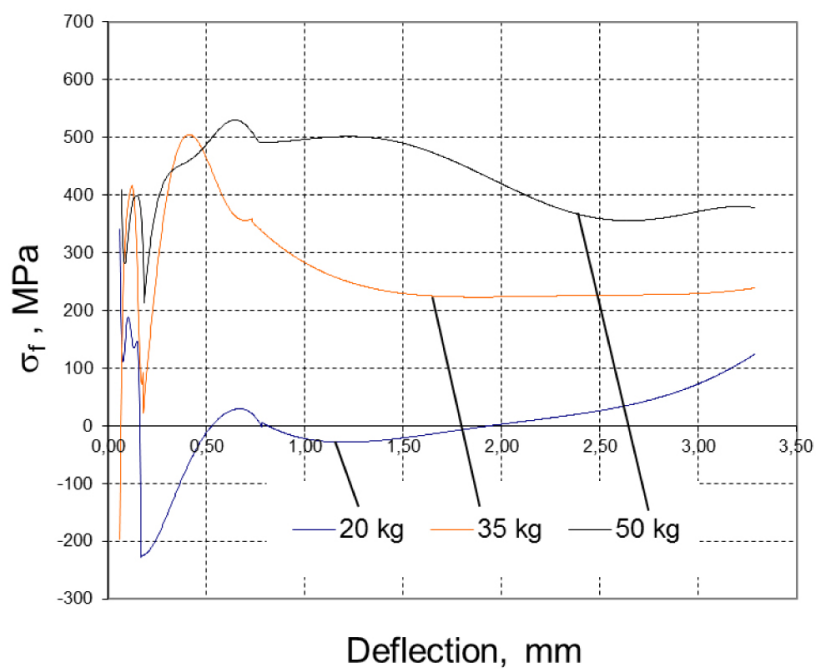

Fig. 14. The relationship of average residual stress and deflections expressed as polynomial function

\section{Conclusions}

1. At the limit bond between ordinary reinforcement and concrete the residual stress could be calculated according to relationship of reinforcement force and curvature of cracked element middle section if to apply the assumption that at the same cracked section curvature the reinforcement force remains also the same independently on amount of fibre.
2. The reinforcement force can be obtained from experimental test of specimens with ordinary reinforcement only. In this case the curvature at the cracked section can be calculated according to deflection increment from crack appearing. It can be obtained from difference between total deflection and deflection of elastic strain.

3. According to relationship of calculated residual stress of tensile fibre and deflection the element resistance can be obtained at each deflection value, so it is possible to obtain the relationship of resistance and deflection

\section{References}

Vandewale L. 2000. Cracking behaviour of concrete beams reinforced with a combination of ordinary reinforcement and steel fibers. Materials and Structures, 2000, Vol. 33, 164 170. http://dx.doi.org/10.1007/BF02479410

Kaklauskas G., Gribniak V., Bačinskas D. 2011. Inverse Technique for Deformational Analysis of Concrete Beams with Ordinary Reinforcement and Steel Fibers. The Proceedings of the Twelfth East Asia-Pacific Conference on Structural Engineering and Construction - EASEC1214 (2011) 14391446.

Grimaldi A., Olivito R. S., Rinaldi Z. 2004. Behaviour of R. C. Beams Reinforced with FRC Material: Analytical Experimental Evaluation. $6^{\text {th }}$ RILEM Symposium of FibreReinforced Concretes (FRC) - BEFIB 2004, Varenna Italy, 1035-1044.

Jones P. A., Austin S. A., Robins P. J. 2008. Predicting the flexural load-deflection response of steel fibre reinforced concrete from strain, crack-width, fibre pull-out and distribution data. Materials and Structures, 2008 Vol. 41, 449-463. http://dx.doi.org/10.1617/s11527-007-9327-9

DIN 1048-5:1991. Testing methods for concrete; hardened concrete, specially prepared specimens.

LST EN 14651:2005+A1:2007 Test Method for Metallic Fibre Concrete - Measuring the flexural tensile strength (Limit Proportionality (LOP), Residual) .

Barr B. I. G., Lee M. K. 2003. Round-robin analysis of the RILEM TC 162-TDF beam bending test: Part 2 - Approximation of 8 from the CMOD response. Materials and Structures, Vol. 36, 2003, 621-630. http://dx.doi.org/10.1007/BF02483282

Received 20130507

Accepted after revision 20130520

Goaras ANDRIUŠIS - lecturer at Kaunas University of Technology, Faculty of Civil Engineering and Architecture, Department of Building Structures.

Main research area: Strength and Stability of Steel Structures.

Address: Kaunas University of Technology, Faculty of Civil Engineering and Architecture, Department of Engineering structures, Studentu st. 48, LT-51367.

Tel.: $\quad+37037300473$

E-mail: Goaras.andriušis@ktu.lt

Algirdas AUGONIS - Lecturer at Kaunas University of Technology, Faculty of Civil Engineering and Architecture, Department of Building Materials.

Main research area: Mechanical Properties of Building Materials.

Address: Kaunas University of Technology, Faculty of Civil Engineering and Architecture, Department of Building Materials, Studentu st. 48, LT-51367.

Tel.: $\quad+37037300465$.

E-mail: algirdas.augonis@ktu.lt 
Mindaugas AUGONIS - associated professor at Kaunas University of Technology, Faculty of Civil Engineering and Architecture, Department of Building Structures.

Main research area: Durability of Engineering Structures, Strength and Stability of Reinforced Concrete Structures.

Address: Kaunas University of Technology, Faculty of Civil Engineering and Architecture, Department of Engineering structures, Studentu st. 48, LT-51367.

Tel.: $\quad+37037300473$

E-mail: mindaugas.augonis@ktu.lt

Šarūnas KELPŠA - PhD student at Kaunas University of Technology, Faculty of Civil Engineering and Architecture. Main research area: Strength and Stability of Reinforced Concrete Structures.

Address: Kaunas University of Technology, Faculty of Civil Engineering and Architecture, Studentu st. 48, LT-51367.

Tel.: $\quad+37037300473$

E-mail: sarunas.kelpsa@gmail.com

Tadas ZINGAILA - Master degree of civil engineering.

Main research area: Strength and Stability of Reinforced Concrete Structures.

Address: UAB “Evikta”, Statybininku st. 12, LT-50127 Kaunas, Lithuania.

E-mail: tadaszingaila@gmail.com 